\title{
2016 yearbook of neurorestoratology
}

\author{
This article was published in the following Dove Press journal: \\ Journal of Neurorestoratology \\ 15 June 2017 \\ Number of times this article has been viewed
}

\section{Hongyun Huang ${ }^{1,2}$ \\ Gengsheng Mao' \\ Shiqing Feng ${ }^{3}$ \\ Lin Chen ${ }^{2,4}$}

'Institute of Neurorestoratology, General Hospital of Armed Police Forces, ${ }^{2}$ Cell Therapy Center, Beijing Hongtianji Neuroscience Academy, Beijing, ${ }^{3}$ Department of Orthopedic, Tianjin Medical University General Hospital, Tianjin, ${ }^{4}$ Department of Neurosurgery, Tsinghua University Yuquan Hospital, Beijing, People's Republic of China
Correspondence: Hongyun Huang Institute of Neurorestoratology, General Hospital of Armed Police Forces, No 69 Rongding Road, Beijing 100039, People's Republic of China

Tel +86 I39 I0II 6608

Email hongyunh@gmail.com
Abstract: Neurorestoratology, a new interdisciplinary field, has gradually become a popular clinical discipline. Physicians and scientists in the neurorestoration field have discovered new pathogeneses of nervous system diseases and damage, explored new neurorestorative mechanisms, and obtained improving neurorestorative effects in clinical trials (or therapies). This paper summarizes the major progress achieved over the past year.

Keywords: yearbook, neurorestoratology, pathogenesis, neural repair and regeneration, central nervous system disease, neurorestorative mechanisms, neurorestorative strategies

\section{Introduction}

Patience is bitter, but its fruit is sweet. Neurorestoratology has gradually become a popular clinical discipline since it was first established as a formal field in $2008 .{ }^{1-4}$ The International Association of Neurorestoratology (IANR), the professional association for this emerging interdisciplinary field, was set up in 2007. Then, the definition of this discipline was clearly made in Beijing Declaration of IANR in 2009. ${ }^{5}$ The Journal of Neurorestoratology (IANR's official journal) published its first paper in 2013. ${ }^{6}$ The Beijing Declaration of IANR was further clarified at the annual IANR conference in Tehran in 2015, which announced that "functional recovery is possible after CNS injury and neurodegeneration." ${ }^{.7}$ This was the first time in world history that a professional medical association repudiated Cajal's thesis ${ }^{8}$ about nervous system regeneration. The goal of neurorestoratology is to restore, promote, and maintain the integrity of impaired or lost neuronal functions and structures - a previously elusive goal. ${ }^{7}$ But over the past decade, several research papers ${ }^{9-11}$ and review books ${ }^{12,13}$ have documented advances in neurorestoration, including therapeutic achievements and exploration of theories and mechanisms. Increasing numbers of researchers, physicians, and even some governments are recognizing the importance of neurorestoratology, with statefunded research efforts such as the US Brain Project, European Human Brain Project, and Chinese and Japanese Brain Project[s] (currently being developed). These efforts are contributing greatly to the following goals: 1) to further identify pathogeneses of nervous system as well as psychological diseases or damage, including dysfunction of perception, movement, autonomic nerve, cognition, memory, intelligence, sleep, etc.; 2) to explore new neurorestorative mechanisms and put forward new neurorestorative theories; and 3) to develop better neurorestorative effects in clinical settings. Significant progress has been made toward all three goals, which we summarize below in the "2016 Yearbook of Neurorestoratology." 


\section{New pathogeneses of nervous system and psychological disease or damage}

During the past year, further findings have been reported based on the basic and classic pathogeneses of nervous diseases or damage. Glasser et $\mathrm{al}^{14}$ reported that a multimodal parcellation of the human cerebral cortex with machine-learning classifier as a tool could correctly locate areas in individuals with atypical parcellations. This breakthrough achievement has the potential to develop neuroanatomical precision of the structural and functional organization in the human cerebral cortex, its variation across individuals, and during the processes of development, aging, and disease. ${ }^{14}$ Setting a powerful and efficient map of human neuroanatomy and functional connectivity can indicate functional representations in the brain. ${ }^{15}$ Through a multimodal approach combining structural information and task-independent (resting state functional magnetic resonance imaging) and task-dependent functional connectivity, disrupted cortico-cingulo circuits were found to promote autism spectrum disorder deficits in attention and social interaction. ${ }^{16}$

Kamat et $\mathrm{al}^{17}$ found that tau hyperphosphorylation and synapse dysfunction might result from oxidative stress, which was mediated through $N$-methyl- $D$-aspartate receptor and their interaction with other molecules. Higher expression of the common $\mathrm{C} 4$ allele or excessive complement activity could reduce numbers of synapses in the brains, which might be one cause for schizophrenia. ${ }^{18}$ Further inappropriately activated microglia in adult brains could engulf synaptic material in a CR3-dependent process when exposed to soluble $A \beta$ oligomers, which might be one cause for the induction of synapse loss in Alzheimer's disease (AD).${ }^{19}$ Major drivers of neurodegeneration may result from complement activation and microglia-mediated synaptic pruning during progranulin deficiency. ${ }^{20}$

Kumar et $\mathrm{al}^{21}$ found that while $\beta$-amyloid might play a protective role in innate immunity against infection or inflammatory stimuli, it might also drive amyloidosis and play a damaging role in AD. Normally, UBQLN2 (proteasome shuttle factor) mediates autophagy-independent clearance of protein aggregates by the proteasome. When there are mutations in UBQLN2, it can lead to neurodegeneration with defects in chaperone binding and impairment of aggregate clearance. $^{22}$

\section{New neurorestorative mechanisms and theories}

Kandu ${ }^{23}$ reported that selectively removing deleterious genome or mutant mtDNA could achieve the goal of treating mitochondrial and aging diseases, such as AD. García Santos $^{24}$ reported that spinal cord injection of bone marrow mononuclear cells for patients with amyotrophic lateral sclerosis (ALS) showed a distant beneficial effect in the brain, in which cells have longer survival and less disability with metabolic improvement. Further exploration needs to be done to know its exact mechanism. Through inhibiting excessively expressed DNA methyltransferases, the function of bone marrow mesenchymal stromal cells (MSCs) derived from ALS patients can be restored..$^{25}$

\section{New clinical evidence for neurorestorative strategies Cell therapy}

Cell-based therapies have been shown to improve the functional abilities of patients and their quality of life, particularly for those suffering from spinal cord injury (SCI), stroke, ALS, multiple sclerosis, cerebral palsy, AD, Parkinson's disease, traumatic brain injury, and other types of CNS diseases and damage. ${ }^{26}$ Below, we summarize the new clinical evidence generated in 2016 for cell therapy to treat neurological disease and damage.

Chronic stroke was treated using human neural stem cells through stereotactic ipsilateral putamen injection, ${ }^{27}$ using bone marrow-derived mesenchymal stem cells through stereotactic injection into the margin of the stroke, ${ }^{28}$ and using autologous M2 cells through intrathecal administration. ${ }^{29}$ These methods restored partial neurological function.

More evidence of improving function for patients with complete chronic SCI has been reported using a variety of different cell-based therapies, including umbilical cord blood-derived mononuclear cell transplants for spinal cord and locomotor training, ${ }^{30}$ the mononuclear-enriched bone marrow cell transplantation through intrathecal infusion, ${ }^{31}$ bone marrow MSC transplantation through lumbar puncture into subarachnoid space, ${ }^{32}$ a combination of neuronal cells differentiated from autologous adipose tissue-derived mesenchymal stem cells, and hematopoietic stem cells through intrathecal infusion, ${ }^{33}$ and olfactory mucosa lamina propria transplants into the spinal cord. ${ }^{34}$

Promising results for patients with ALS have been reported by intraspinal injection of bone marrow-derived neural stem cells, in which patients experienced a temporary stabilization for the first few months postinjection and then gradually deteriorated. ${ }^{35}$ Transplantation of inducing mesenchymal stem cells to secrete neurotrophic factors by intramuscular and intrathecal injections has shown at least 
$25 \%$ improvement at 6 months after treatment in the slope of progression for patients with ALS. ${ }^{36}$

Even patients diagnosed with an aggressive form of multiple sclerosis over a prolonged period have substantially recovered their neurological function following autologous hemopoietic stem cell transplantation. ${ }^{37}$ Canesi et $\mathrm{al}^{38}$ reported that bone marrow MSC administration for patients with progressive supranuclear palsy could clinically stabilize the condition for at least 6 months, a significant outcome given the invariably rapid deterioration of motor function.

Cox et $\mathrm{al}^{39}$ reported that intravenously delivered autologous bone marrow mononuclear cell infusion for severe adult traumatic brain injury appears to play a role in CNS structural preservation. Vaquero et $\mathrm{al}^{40}$ found that intrathecal administration of autologous MSCs in patients with diffuse axonal injury could improve neurological functions and show a diffuse and progressive increase in brain glucose metabolism.

Some case reports also showed benefits of cell therapy for patients with postpoliomyelitis syndrome ${ }^{41}$ and primary torsion dystonia. ${ }^{42}$

\section{Neuromodulation and the brain- computer interface}

Neuromodulation and the brain-computer interface provides one of most promising strategies in neurorestoratology. ${ }^{13}$ Bouton et $\mathrm{al}^{43}$ reported that intracortically recorded signals could be decoded to extract information related to motion (imagined movements), allow paralyzed humans to restore cortical control of functional movement, and control computer and robotic arms through a custom-built highresolution neuromuscular electrical stimulation system. Vansteensel et $\mathrm{al}^{44}$ reported that the locked-in patient with ALS could accurately and independently control a computer typing program for autonomous communication with implanted brain-computer interface. Flesher et $\mathrm{al}^{45}$ reported that intracortical microstimulation of the human somatosensory cortex could evoke tactile sensations perceived as originating from locations on the hand for patients with long-term SCI who had lost feeling. Donati et $\mathrm{al}^{46}$ reported that eight paraplegic patients recovered partial neurological functions by 12-month training with a brain-machine interface-based gait protocol.

\section{Neurorestorative surgery}

Several kinds of neurorestorative surgeries have been able to help patients with central nervous damage restore their neurological functioning ${ }^{13}$ since Carlsson and Sundin ${ }^{47}$ reported their results of reconstruction of efferent pathways to the urinary bladder in 1967 . Tuite et $\mathrm{al}^{48}$ reported from their clinical trial that the Xiao procedure for restoring bladder and bowel function did not result in voluntary voiding or continence in any patient, but patients undergoing spinal cord detethering plus the Xiao procedure were more likely to have greater improvements in total bladder capacity, bladder overactivity control, and overall quality of life than those who underwent detethering only. The explanation for this improvement may be related to sacral nerve root sectioning, instead of reinnervation. Yang ${ }^{49}$ reported that revascularization in sickle cell disease patients with Moyamoya syndrome could prevent stroke recurrence. Comparing various reanimation techniques such as facial nerve interpositional graft, hypoglossal-facial nerve transfer, and direct end-to-side facial-hypoglossal anastomosis, Mohamed et $\mathrm{al}^{50}$ concluded that the latter technique through epineural suture is the most effective method with excellent outcomes for facial reanimation. Kochhar et $\mathrm{al}^{51}$ reported that facial nerve direct end-to-end coadaptation to the hypoglossal nerve was effective in restoring facial tone and symmetry after facial paralysis.

\section{Pharmaceutical}

So far, there are many pharmaceutical interventions for neurorestoration, but most of them have failed their aims when tested in clinical trials. ${ }^{13}$ Although delivering granulocytecolony stimulating factor is a feasible treatment for chronic stroke, a research study found that this did not demonstrate functional recovery. ${ }^{52}$ More promising lines of research have demonstrated that erythropoietin and granulocyte-colony stimulating factor combination therapy may improve the functional abilities of stroke patients ${ }^{53}$ dl-3-n-butylphthalide significantly increased the level of circulation and improved clinical outcome in patients with acute ischemic stroke. ${ }^{54}$

\section{Summary}

Much exploration has been done and many valuable results have been achieved over the course of 2016 for understanding the pathogeneses of nervous system diseases and damage, exploring neurorestorative mechanisms, and seeking more effective therapeutic strategies in the field of neurorestoratology. We firmly believe that there will be a step-by-step progress in neurorestoratology in the future, especially therapeutic strategies for improving neurorestorative effects. While the existing literature on cell therapies for CNS diseases and damage have demonstrated that these procedures are relatively safe and produce effective results, we still need more multicenter, randomized, controlled, double-blind studies and trials with larger sample sizes in order to establish the 
long-term risks and benefits for patients now and in the near future - learning from yesterday and working harder today in order to make a better tomorrow.

\section{Disclosure}

The authors report no conflicts of interest in this work.

\section{References}

1. Huang H, Chen L. Neurorestoratology—new subject, new principle, new field in 21st century. J Repar Reconstr Surg. 2008;22:439-445.

2. Chen L, Huang H. Neurorestoratology: new concept and bridge from bench to bedside. Zhongguo Xiu Fu Chong Jian Wai Ke Za Zhi. 2009;23:366-370.

3. Huang H, Sharma H. Neurorestoratology: one of the most promising new disciplines at the forefront of neuroscience and medicine. $J \mathrm{Neu}$ rorestoratol. 2013;1:37-41.

4. Huang L, Chen L. Neurorestoratology: a concept and emerging discipline in the treatment of neurological disorders. CNS Neurol Disord Drug Targets. 2016;15(5):522-525.

5. IANR (International Association of Neurorestoratology). Beijing declaration of international association of neurorestoratology (IANR). Cell Transplant. 2009;18:487.

6. Gao J, Thonhoff JR, Dunn TJ, Wu P. Lipoic acid enhances survival of transplanted neural stem cells by reducing transplantation-associated injury. J Neurorestoratol. 2013;1:1-12.

7. Young W, AlZoubi Z, Saberi H, et al. Beijing declaration of international association of neurorestoratology (IANR). J Neurorestoratol. 2015,3:121-122.

8. Cajal SRY. Degeneration and Regeneration of the Nervous System (May RM, Trans.). London: Oxford University Press; 1928.

9. Huang H, Chen L, Sanberg PR. Clinical achievements, obstacles, falsehoods, and future directions of cell-based neurorestoratology. Cell Transplant. 2012;21(Suppl 1):S3-S11.

10. Huang H, Sun T, Chen L, et al. Consensus of clinical neurorestorative progress in patients with complete chronic spinal cord injury. Cell Transplant. 2014;23(Suppl 1):S5-S17.

11. Huang H, Chen L. Neurorestorative process, law, and mechanisms. J Neurorestoratol. 2015;3:23-30.

12. Huang H. CNS Neurorestoratology. Beijing: Science Press; 2009.

13. Huang H, Raisman G, Sanberg PR, Sharma H, Chen L. Neurorestoratology. New York, NY: Nova Biomedical; 2015.

14. Glasser MF, Coalson TS, Robinson EC, et al. A multi-modal parcellation of human cerebral cortex. Nature. 2016;536(7615):171-178.

15. Huth AG, de Heer WA, Griffiths TL, Theunissen FE, Gallant JL. Natural speech reveals the semantic maps that tile human cerebral cortex. Nature. 2016;532(7600):453-458.

16. Balsters JH, Mantini D, Apps MA, Eickhoff SB, Wenderoth N. Connectivity-based parcellation increases network detection sensitivity in resting state fMRI: An investigation into the cingulate cortex in autism. Neuroimage Clin. 2016;11:494-507.

17. Kamat PK, Kalani A, Rai S, et al. Mechanism of oxidative stress and synapse dysfunction in the pathogenesis of alzheimer's disease: understanding the therapeutics strategies. Mol Neurobiol. 2016;53(1):648-661.

18. Sekar A, Bialas AR, de Rivera H, et al; Schizophrenia Working Group of the Psychiatric Genomics Consortium. Schizophrenia risk from complex variation of complement component 4. Nature. 2016;530(7589): 177-183.

19. Hong S, Beja-Glasser VF, Nfonoyim BM, et al. Complement and microglia mediate early synapse loss in Alzheimer mouse models. Science. 2016;352(6286):712-716.

20. Lui H, Zhang J, Makinson SR, et al. Progranulin deficiency promotes circuit-specific synaptic pruning by microglia via complement activation. Cell. 2016;165(4):921-935.
21. Kumar DK, Choi SH, Washicosky KJ, et al. Amyloid- $\beta$ peptide protects against microbial infection in mouse and worm models of Alzheimer's disease. Sci Transl Med. 2016;8(340):340ra72.

22. Hjerpe R, Bett JS, Keuss MJ, et al. UBQLN2 mediates autophagyindependent protein aggregate clearance by the proteasome. Cell. 2016;166(4):935-949.

23. Kandul NP, Zhang T, Hay BA, Guo M. Selective removal of deletionbearing mitochondrial DNA in heteroplasmic Drosophila. Nat Commun. 2016;7:13100.

24. García Santos JM, Inuggi A, Gómez Espuch J, et al. Spinal cord infusion of stem cells in amyotrophic lateral sclerosis: magnetic resonance spectroscopy shows metabolite improvement in the precentral gyrus. Cytotherapy. 2016;18(6):785-796.

25. Oh YS, Kim SH, Cho GW. Functional restoration of amyotrophic lateral sclerosis patient-derived mesenchymal stromal cells through inhibition of DNA Methyltransferase. Cell Mol Neurobiol. 2016;36(4): 613-620.

26. Huang H, Mao G, Chen L, Liu A. Progress and challenges with clinical cell therapy in neurorestoratology. J Neurorestoratol. 2015;3: 91-95.

27. Kalladka D, Sinden J, Pollock K, et al. Human neural stem cells in patients with chronic ischaemic stroke (PISCES): a phase 1, first-in-man study. Lancet. 2016;388(10046):787-796.

28. Steinberg GK, Kondziolka D, Wechsler LR, et al. Clinical outcomes of transplanted modified bone marrow-derived mesenchymal stem cells in stroke: a phase 1/2a study. Stroke. 2016;47(7):1817-1824.

29. Chernykh ER, Shevela EY, Starostina NM, et al. Safety and therapeutic potential of M2 macrophages in stroke treatment. Cell Transplant. 2016;25(8):1461-1471.

30. Zhu H, Poon W, Liu Y, et al. Phase III clinical trial assessing safety and efficacy of umbilical cord blood mononuclear cell transplant therapy of chronic complete spinal cord injury. Cell Transplant. 2016;25(11):1925-1943.

31. Kakabadze Z, Kipshidze N, Mardaleishvili K, et al. Phase 1 trial of autologous bone marrow stem cell transplantation in patients with spinal cord injury. Stem Cells Int. 2016;2016:6768274.

32. Vaquero J, Zurita M, Rico MA, et al; Neurological Cell Therapy Group. An approach to personalized cell therapy in chronic complete paraplegia: the Puerta de Hierro phase I/II clinical trial. Cytotherapy. 2016;18(8):1025-1036.

33. Thakkar UG, Vanikar AV, Trivedi HL, et al. Infusion of autologous adipose tissue derived neuronal differentiated mesenchymal stem cells and hematopoietic stem cells in post-traumatic paraplegia offers a viable therapeutic approach. Adv Biomed Res. 2016;5:51.

34. Wang S, Lu J, Li YA, et al. Autologous olfactory lamina propria transplantation for chronic spinal cord injury: three-year follow-up outcomes from a prospective double-blinded clinical trial. Cell Transplant. 2016;25(1):141-157.

35. Nafissi S, Kazemi H, Tiraihi T, et al. Intraspinal delivery of bone marrow stromal cell-derived neural stem cells in patients with amyotrophic lateral sclerosis: a safety and feasibility study. J Neurol Sci. 2016;362:174-181.

36. Petrou P, Gothelf Y, Argov Z, et al. Safety and clinical effects of mesenchymal stem cells secreting neurotrophic factor transplantation in patients with amyotrophic lateral sclerosis: results of phase $1 / 2$ and 2 a clinical trials. JAMA Neurol. 2016;73(3):337-344.

37. Atkins HL, Bowman M, Allan D, et al. Immunoablation and autologous haemopoietic stem-cell transplantation for aggressive multiple sclerosis: a multicentre single-group phase 2 trial. Lancet. 2016;388(10044):576-585.

38. Canesi M, Giordano R, Lazzari L, et al. Finding a new therapeutic approach for no-option parkinsonisms: mesenchymal stromal cells for progressive supranuclear palsy. J Transl Med. 2016;14(1):127.

39. Cox CS Jr, Hetz RA, Liao GP, et al. Treatment of severe adult traumatic brain injury using bone marrow mononuclear cells. Stem Cells. 2017;35(4): 1065-1079. 
40. Vaquero J, Zurita M, Bonilla C, et al. Progressive increase in brain glucose metabolism after intrathecal administration of autologous mesenchymal stromal cells in patients with diffuse axonal injury. Cytotherapy. 2017;19(1):88-94.

41. Xi HT, Chen D. Cell-based neurorestorative therapy for postpoliomyelitis syndrome: a case report. J Neurorestoratology. 2016,4:45-50.

42. Ren WQ, Yin F, Zhang JN, et al. Neural stem cell transplantation for the treatment of primary torsion dystonia: a case report. Exp Ther Med. 2016;12(2):661-666.

43. Bouton CE, Shaikhouni A, Annetta NV, et al. Restoring cortical control of functional movement in a human with quadriplegia. Nature. 2016;533(7602):247-250.

44. Vansteensel MJ, Pels EG, Bleichner MG, et al. Fully implanted braincomputer interface in a locked-in patient with ALS. $N$ Engl J Med. 2016;375(21):2060-2066.

45. Flesher SN, Collinger JL, Foldes ST, et al. Intracortical microstimulation of human somatosensory cortex. Sci Transl Med. 2016;8(361): 361 ra141.

46. Donati AR, Shokur S, Morya E, et al. Long-term training with a brainmachine interface-based gait protocol induces partial neurological recovery in paraplegic patients. Sci Rep. 2016;6:30383.

47. Carlsson CA, Sundin T. Reconstruction of efferent pathways to the urinary bladder in a paraplegic child. Rev Surg. 1967;24(1):73-76.
48. Tuite GF, HomsyY, Polsky EG, et al. Urological outcome of the xiao procedure in children with myelomeningocele and lipomyelomeningocele undergoing spinal cord detethering. J Urol. 2016;196(6):1735-1740.

49. Yang W, Porras JL, Xu R, et al. Effectiveness of surgical revascularization for stroke prevention in pediatric patients with sickle cell disease and moyamoya syndrome. Neurosurgery. 2016;63(Suppl 1):178.

50. Mohamed A, Omi E, Honda K, Suzuki S, Ishikawa K. Outcome of different facial nerve reconstruction techniques. Braz J Otorhinolaryngol. 2016;82(6):702-709.

51. Kochhar A, Albathi M, Sharon JD, Ishii LE, Byrne P, Boahene KD. Transposition of the intratemporal facial to hypoglossal nerve for reanimation of the paralyzed face: The VII to XII transposition technique. JAMA Facial Plast Surg. 2016;18(5):370-378.

52. Sprigg N, O’Connor R, Woodhouse L, et al. Granulocyte colony stimulating factor and physiotherapy after stroke: results of a feasibility randomised controlled trial: stem cell trial of recovery EnhanceMent after stroke-3 (STEMS-3 ISRCTN16714730). PLoS One. 2016;11(9):e0161359.

53. Shin YK, Cho SR. Exploring erythropoietin and G-CSF combination therapy in chronic stroke patients. Int J Mol Sci. 2016;17(4):463.

54. Zhao H, Yun W, Zhang Q, et al. Mobilization of circulating endothelial progenitor cells by dl-3-n-Butylphthalide in acute ischemic stroke patients. J Stroke Cerebrovasc Dis. 2016;25(4):752-760.
Journal of Neurorestoratology

\section{Publish your work in this journal}

The Journal of Neurorestoratology is an international, peer-reviewed, open access online journal publishing original research and review articles on the subject of Neurorestoratology. To provide complete coverage of this revolutionary field the Journal of Neurorestoratology will report on relevant experimental research, technological advances,

\section{Dovepress}

and clinical achievements. The manuscript management system is completely online and includes a very quick and fair peer-review system, which is all easy to use. Visit http://www.dovepress.com/testimonials. php to read real quotes from published authors. 